\title{
BMJ Open Need for recovery amongst emergency physicians in the UK and Ireland: a cross-sectional survey
}

\author{
Laura Cottey (D) ,1,2 Tom Roberts (D) , ${ }^{3}$ Blair Graham (1D) , ${ }^{1,4}$ Daniel Horner (D) , ,,5,6 \\ Kara Nicola Stevens (D) , ${ }^{7}$ Doyo Enki (D) , ${ }^{8}$ Mark David Lyttle (1) , ${ }^{9,10}$ Jos Latour (D) , ${ }^{4}$ \\ Trainee Emergency Research Network (TERN) and Paediatric Emergency Research \\ in the UK and Ireland (PERUKI)
}

To cite: Cottey L, Roberts T, Graham B, et al. Need for recovery amongst emergency physicians in the UK and Ireland: a crosssectional survey. BMJ Open 2020;10:e041485. doi:10.1136/ bmjopen-2020-041485

- Prepublication history and additional material for this paper are available online. To view these files, please visit the journal online (http://dx.doi. org/10.1136/bmjopen-2020041485).

Received 09 June 2020 Revised 26 August 2020 Accepted 21 September 2020

Check for updates

(C) Author(s) (or their employer(s)) 2020. Re-use permitted under CC BY-NC. No commercial re-use. See rights and permissions. Published by BMJ.

For numbered affiliations see end of article.

Correspondence to

Dr Laura Cottey;

laurajcottey@gmail.com

\section{ABSTRACT}

Objectives To determine the need for recovery (NFR) among emergency physicians and to identify demographic and occupational characteristics associated with higher NFR scores.

Design Cross-sectional electronic survey.

Setting Emergency departments (EDs) $(n=112)$ in the UK and Ireland.

Participants Emergency physicians, defined as any registered physician working principally within the ED, responding between June and July 2019.

Main outcome measure NFR Scale, an 11-item selfadministered questionnaire that assesses how work demands affect intershift recovery.

Results The median NFR Score for all 4247 eligible, consented participants with a valid NFR Score was 70.0 (95\% Cl: 65.5 to 74.5 ), with an IQR of 45.5-90.0. A linear regression model indicated statistically significant associations between gender, health conditions, type of $E D$, clinical grade, access to annual and study leave, and time spent working out-of-hours. Groups including male physicians, consultants, general practitioners (GPs) within the ED, those working in paediatric EDs and those with no long-term health condition or disability had a lower NFR Score. After adjusting for these characteristics, the NFR Score increased by 3.7 (95\% Cl: 0.3 to 7.1$)$ and 6.43 (95\% $\mathrm{Cl}: 2.0$ to 10.8$)$ for those with difficulty accessing annual and study leave, respectively. Increased percentage of out-of-hours work increased NFR Score almost linearly: $26 \%-50 \%$ out-of-hours work $=5.7$ (95\% Cl: 3.1 to 8.4 ); $51 \%-75 \%$ out-of-hours work $=10.3$ (95\% Cl: 7.6 to 13.0 ); $76 \%-100 \%$ out-of-hours work $=14.5(95 \% \mathrm{Cl}: 11.0$ to 17.9).

Conclusion Higher NFR scores were observed among emergency physicians than reported in any other profession or population to date. While out-ofhours working is unavoidable, the linear relationship observed suggests that any reduction may result in NFR improvement. Evidence-based strategies to improve well-being such as proportional out-of-hours working and improved access to annual and study leave should be carefully considered and implemented where feasible.
Strengths and limitations of this study

- This is the first study evaluating the Need for Recovery (NFR) Scale within a large healthcare population.

- The inclusion of responses from over half of all UK emergency departments indicates the results are likely to be generalisable.

- The high volume of responses, with over half of study sites exceeding $70 \%$ participant response rates, indicates that the NFR Scale is an acceptable measurement tool for physicians.

- The study is limited by the single point of time measurement; therefore, seasonal bias cannot be excluded and further assessment of test-retest reliability is desirable.

- The use of self-administered dichotomous questionnaires is acknowledged to limit wider insights into physician recovery and well-being.

\section{INTRODUCTION}

Recruitment and retention challenges in acute care pose a significant and ongoing threat to effective healthcare provision. The need to maintain a healthy and sustainable workforce is vital to safeguard future services. ${ }^{1}$ Physician well-being is a key influence on retention, with low job satisfaction and high levels of stress directly leading to concern over job sustainability. ${ }^{2-4}$ Globally, high rates of physician burnout are increasingly recognised, along with the consequent negative impact on delivery of high-quality patient care. ${ }^{5-10}$

The Need for Recovery (NFR) Scale measures the subjective perception of the need to recuperate from the physical and mental demands of a working day, and is a suitable tool with which to assess the early symptoms of fatigue in shift workers. ${ }^{11} 12$ Within unscheduled care settings such as emergency medicine (EM), shift work is often of high intensity, and additional factors such as 
department crowding, pressured resources and inability to control patient volume may also influence NFR. Where fatigue does occur and cannot be sufficiently recovered between shifts, the effect is cumulative and may lead to increased occupational stress and impaired long-term health. ${ }^{13} 14$

Burnout inventories are increasingly used as an attempt to measure physician well-being. ${ }^{15}$ Although they provide valuable insight into well-being, they are not without issue. Limitations include variability in burnout definitions, time required for completion, ease of completion, respondent survey fatigue and difficulty translating results into intervention. ${ }^{16-18}$ Additionally, these methods quantify established burnout; once this has occurred the human and financial resource impact is already immense, with associated workforce depletion and negligible mitigation strategies. ${ }^{192}$ The identification of those clinicians at risk of burnout, at an early timepoint when interventions may be effective, presents a critical challenge.

Increasing NFR is associated with the likelihood of progression to occupational burnout and health complaints, with negative effects cumulative over time in several validation studies. ${ }^{11} 13$ Increased NFR may, therefore, precede the onset of sustained occupational burnout, and offer advantages over other burnout inventories as a simple quantifiable metric obtained through a rapid, standalone and repeatable 11-item questionnaire. A single-centre study assessing the utility of the NFR in an emergency department (ED) population reported a high response rate $(80 \%)$ and completion time of less than 10 min while gaining insight into shift patterns, worklife balance and well-being. ${ }^{21}$ This might suggest that the method of questioning used in the NFR Scale and emphasis on recovery as opposed to more emotive questioning could be beneficial in improving response rates and reducing respondent fatigue in repeat usage. As such, NFR may provide a valuable option for regular evaluating of staff well-being and identifying opportunity for early intervention in busy EDs. Staff well-being is the fourth highest EM research priority identified by the James Lind Alliance Priority Setting Partnership, involving patients, carers and physicians. ${ }^{22}$

We, therefore, aimed to determine the NFR among emergency physicians in EDs in the UK and Ireland, and identify demographic and occupational characteristics associated with higher NFR scores that might allow for early targeted intervention to improve physicians' wellbeing and reduce burnout.

\section{METHODS}

This cross-sectional electronic survey study targeted a representative sample of emergency physicians working across the UK and Ireland, and was performed and reported in line with the Checklist for Reporting Results of Internet E-Surveys. ${ }^{23}$ The study was registered at the International Standard Randomised Control Trial
Number (ISRCTN) registry (https://doi.org/10.1186/ ISRCTN21869845).

\section{Settings and participants}

An initial sample of 100 EDs was deemed necessary to ensure inclusion of greater than $50 \%$ of type $1 \mathrm{EDs}$, defined as 'an EM consultant-led 24-hour service with full resuscitation facilities', in England. ${ }^{24}$ The study was coordinated via the UK Trainee Emergency Research Network (TERN) and delivered in collaboration with Paediatric Emergency Research in the UK and Ireland (PERUKI) and Ireland TERN. ${ }^{25}{ }^{26}$ Signposting to the survey and enrolment of participants was led by site principal investigators (PIs), who were provided with standardised study documentation. Local and national promotion of the study was conducted at professional meetings, through social media, national newsletters and using the Clinical Research Network infrastructure.

Physicians of any grade who were registered with either the UK General Medical Council or Irish Medical Council, and who were employed within a participating $\mathrm{ED}$, were invited to participate. For the purposes of this study, the term emergency physician is defined as all doctors working within the ED. This included; doctors specialising in EM, with specialty training comprising at least 6 years of postgraduate training for full qualification to achieve the grade of EM consultant, and non-EM specialists undertaking rotations in the ED as part of their professional training, including those in the first and second year of postgraduate training and physicians undertaking training in General Practice, Anaesthesia and Acute Medicine who commonly complete a 4-6 month ED rotation (online supplemental material 1). Physicians who did not hold a permanent contract with a participating hospital (such as those working ad-hoc locum shifts), those on leave during the study period, and those in a non-clinical role were excluded.

\section{Survey development}

The NFR Scale consists of 11 items each requiring a dichotomous 'yes' or 'no' response, originally developed as a subscale of the Dutch Questionnaire on the Experience and Evaluation of Work (online supplemental material 2, p. 10). ${ }^{27}$ Indicators of fatigue such as reduced motivation for activities and concentration at the end of a working day are assessed to measure the effect of work demands experienced. A 'yes' response to an item, with the exception of question four which is reversed, signals an unfavourable situation. The total sum of the unfavourable responses is multiplied by 100 and divided by the total number of scale items, 11, producing an overall score between 0 and 100 , with a higher score denoting a greater NFR and increased short-term work-related fatigue. The NFR Scale has previously been demonstrated to have an overall Cronbach's alpha of 0.88 , a measure of internal consistency and questionnaire reliability, with a range of 0.81-0.92 in subgroup analyses of the same validation study. ${ }^{28}$ Following a minor amendment to one question to 
increase applicability to the study population (from 'after the evening meal, I generally feel in good shape' to 'after my breaks, I feel fresh to continue my work'), feasibility work in a single UK centre demonstrated a Cronbach's alpha of 0.79 , and found that the NFR Scale was acceptable and user friendly. ${ }^{21}$

A patient and public involvement consultation was conducted at the UK Emergency Medicine Trainee Association Conference (Cardiff, December 2018), using a semistructured question guide for mixed focus groups to review a proposed participant survey. A key element of this consultation explored the use of a burnout inventory within the proposed study; concerns relating to respondent fatigue, length of survey and assessment of questions using a Likert Scale indicated that such an inventory was not universally acceptable to emergency physicians. Based on this consultation, the final participant survey included the 11-item NFR Scale used in the feasibility work and 44-items collecting the participants' demographic, occupational and perceived well-being characteristics (online supplemental material 2). Questions relating to 'outof-hours' work were defined as work outside of normal working office hours (09:00 until 17:00, Monday to Friday).

A separate site-specific survey was developed de novo with expert input from experienced emergency physicians, consisting of 39 items identified from the literature and/or consensus of the study team, which explored departmental, rota pattern and staffing characteristics likely to provide context for analysis and interpretation of individual survey results (online supplemental material 3). Only one site-specific survey was required per participating centre and was completed by the site PI.

\section{Survey distribution, monitoring and recruitment}

All participants were provided with an information sheet, and consented to participation prior to completing the survey; this was voluntary, anonymous and no incentives were given. Respondents were able to review and change their answers prior to final submission of the survey. Branching logic was used for responses to certain questions. Data were collected during a 6-week period from 3 June 2019. During this period, advertisement of the survey and weekly reminders were sent out via site PIs. The participant and site-specific surveys were open surveys accessed through a link and hosted on a research-specific electronic survey platform, Research Electronic Data Capture platform (University of Bristol), which complies with European General Data Protection Regulations. ${ }^{29} 30$

Prior to study commencement, site PIs provided a best estimate of eligible participants which accounted for local physician absence due to sickness, leave and factors such as sabbaticals and professional secondments. This denominator was used to give a best estimate of the persite survey response rate, with a stated aim of achieving a $70 \%$ response rate.

\section{Statistical analysis}

Statistical analysis was undertaken using STATA V.14. ${ }^{31}$ Participants were only included in any of the reported analyses if they were from 1 of the 112 registered sites and provided a response for at least 8 of the 11 items of the NFR Scale as per imputation guidelines. Imputation was performed by replacing missing items with the mean of all completed item responses. ${ }^{32}$

As one item in the NFR Scale was amended due to applicability to the study population, the internal consistency of the NFR Scale for all participants with a valid NFR Score was calculated by Cronbach's alpha.

To describe the study sample, the frequency and percentage of participants by site, demographic and occupational characteristics are reported. As the distribution of the NFR Score in this study was negatively skewed, summary statistics of the median NFR Score are reported with corresponding bootstrapped 95\% CIs from 1000 replications (providing there are at least eight observations to allow for sufficient number of sample combinations), and IQR of all eligible participants. Box plots were used as visual aids to identify covariates that may have a statistically significant association with the NFR Score and the nature of the relationship.

Table 1 Characteristics of sites registered to take part in the survey study

\begin{tabular}{lc}
\hline Site characteristics & $\begin{array}{c}\text { N (\%) } \\
\text { Total=112 }\end{array}$ \\
\hline Country & $89(79.5)$ \\
England & $3(2.7)$ \\
Wales & $3(2.7)$ \\
\hline Northern Ireland & $12(10.7)$ \\
\hline Scotland & $5(4.4)$ \\
\hline Ireland & \\
\hline ED annual attendance & $11(9.8)$ \\
\hline$\leq 50$ 000 & $46(41.1)$ \\
\hline 50 001-100 000 & $42(37.5)$ \\
\hline$>100$ 000 & $13(11.6)$ \\
\hline Missing & \\
\hline Specialist designation & $55(49.1)$ \\
\hline Trauma unit* & $25(22.3)$ \\
\hline Major trauma centre (MTC)† & $42(37.5)$ \\
\hline Stroke centre & $30(26.8)$ \\
\hline PCl centre &
\end{tabular}

*In the UK National Health Service, a hospital that provides care for all except the most severe major trauma patients. May provide initial stabilisation of severely injured patients prior to transfer to an MTC.

$\dagger A$ specialist (tertiary) centre responsible for care of the most severely injured patients.

$\mathrm{ED}$, emergency department; $\mathrm{PCl}$, percutaneous coronary intervention. 
A

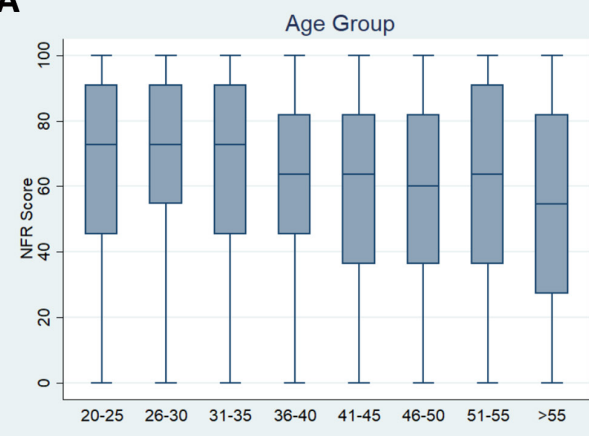

C

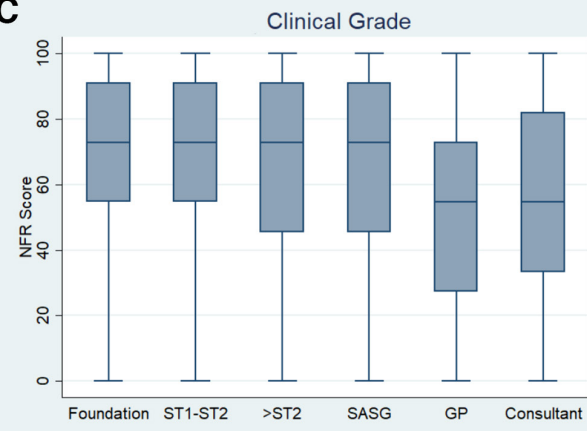

B

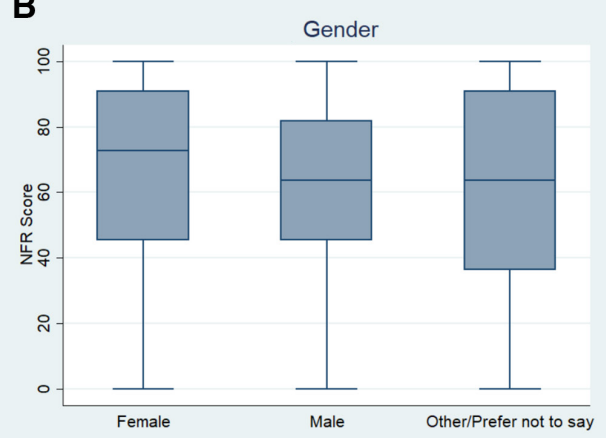

D

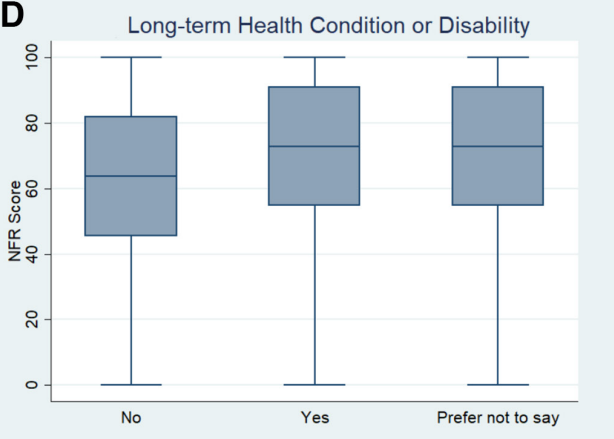

Figure 1 Box plots of Need for Recovery (NFR) Score by participant demographic characteristics, excluding any participants who did not respond to the question (ie, missing). Plot (A) age group in years; (B) gender; (C) clinical grade; (D) any long-term health condition or disability. ST1-ST2, specialist training year 1-2 (this included physicians training in anaesthetics, emergency medicine (EM), acute medicine and general practice); SASG, EM staff grade, associate specialist and specialty grade physician; GP, general practitioner working within the emergency department (ED).

To facilitate comparisons with the previous published literature and given the large number of participants, we fitted Gaussian, mixed effects, linear regression models to NFR Score, where site was included as a random effect to account for potentially unknown differences between EDs. To identify statistically significant associations between the NFR Score and observed covariates, the forward model selection procedure was implemented; inclusion in the model was based on the goodness of fit test at the $5 \%$ level of significance, using only participants with complete NFR Score and covariate data. The final model was estimated using participants with complete data for the included covariates and NFR Score, with the coefficient estimate calculated by adjusting for all covariates reported in the model. Quantile regression was used to confirm the direction and significance of the identified associations under non-parametric assumptions.

\section{RESULTS}

Characteristics of the 112 participating sites are presented in table 1.

Of 5107 unique visits to the online survey, 4365 of these were registered at 1 of the 112 sites and provided consent, with 4247 completing at least 8 items of the NFR Scale. Cronbach's alpha for all participants with a valid NFR Score was 0.80 . The median NFR Score across all eligible participants was 70.0 (95\% CI: 65.5 to 74.5 ), with an IQR of 45.5-90.0. Figures 1 and 2 and tables 2 and 3 present a selection of participant's NFR Score by demographic and occupational characteristics, with additional characteristics presented in the online supplemental material 4.

Only $7.5 \%$ of the participants were aged over 50 years, and the majority were aged between 26 and 30 years $(28.6 \%)$. NFR Score appeared to decrease with age, such that those in age groups 20-35 years all had a median score of 72.7, age groups 36-55 had a median score of 63.6, and those over 55 years had a median score of 54.5 (figure 1A). There was a reasonable balance between males and females, with just over $1 \%$ who did not submit a response (missing), preferred not to say or other. Females had a higher median NFR Score of 72.7 (95\% CI: 70.5 to 75.0) compared with males 63.6 (95\% CI: 60.8 to 66.5 ) (figure 1B). Within clinical grade, consultants accounted for over a quarter of the participants who (with GPs) had the lowest median NFR Score of 54.5 (consultants 95\% CI: 53.6 to 55.5) compared with 72.7 in all other grades (figure 1C). The majority of participants had no long-term health conditions or disability (88.6\%), with a lower NFR Score of 63.6 (95\% CI: 60.2 to 67.1) compared with those who did report a long-term health condition or disability 72.7 (95\% CI: 66.2 to 79.2 ) (figure 1D). Most participants worked full time $(83.5 \%)$, but overall, the NFR Score did not decrease as contract proportion decreased (table 2). Over half $(54.6 \%)$ had been working in their current ED for 1 year or less and generally had higher NFR scores compared with those present for over 
A

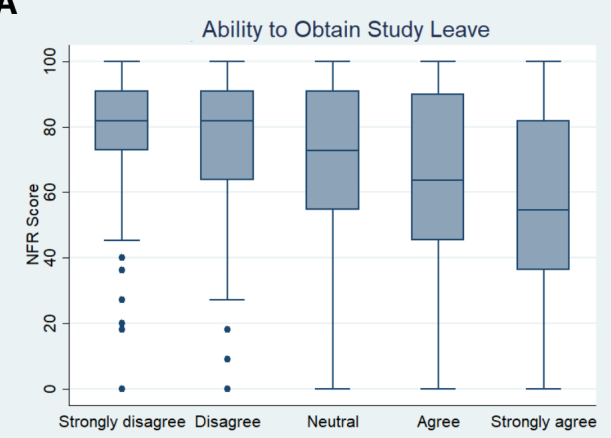

C

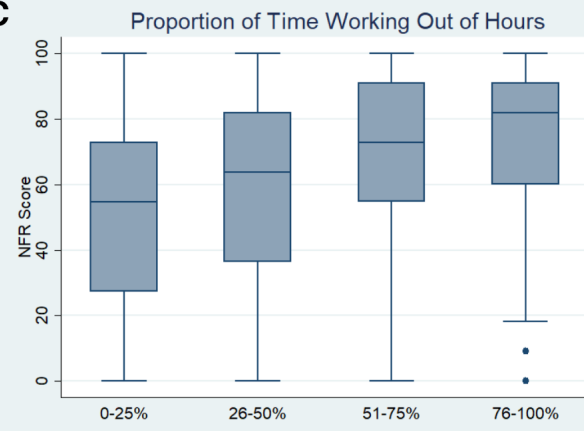

B

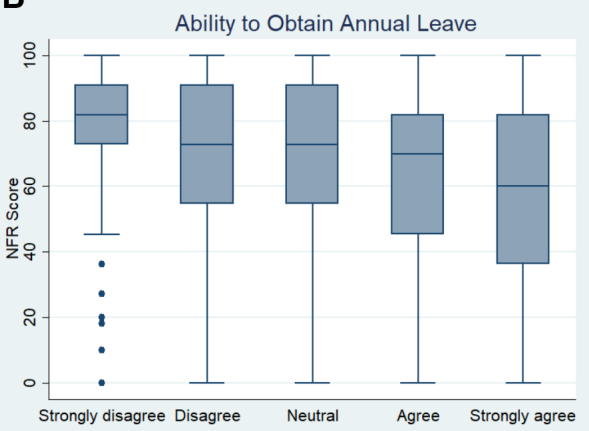

D

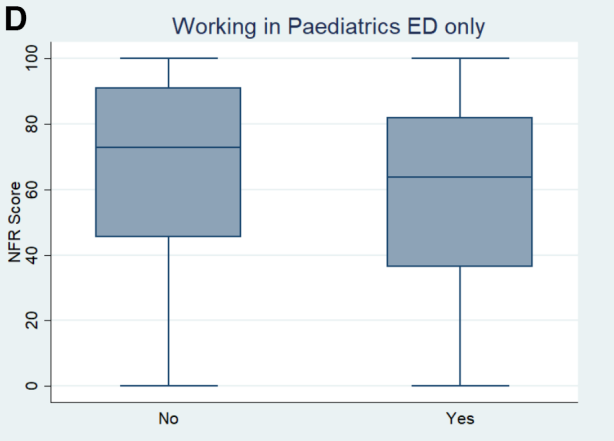

Figure 2 Box plot of Need for Recovery (NFR) Score by participant's occupational characteristics, excluding any participants who does not respond to the question (ie, missing). Plot (A) ability to obtain study leave when requested; (B) ability to obtain annual leave when requested; (C) proportion of time working out-of-hours; (D) working in paediatrics emergency departments (ED) only.

1 year. Less than $35 \%$ of participants declared significant caring responsibilities outside of work, but those who do had a lower median NFR Score (63.6, 95\% CI: 62.8 to $64.5)$ than those who did not (72.7, $95 \%$ CI: 68.5 to 77.0$)$.

Most of the participants agreed or strongly agreed they were able to obtain study or annual leave when requested ( $68 \%$ and $>73 \%$, respectively). As the ability to obtain study and annual leave on request increased, the NFR Score decreased from 81.8 (95\% CI: 81.4 to 82.2 ) to 54.5 (95\% CI: 49.4 to 59.7) for study leave and 81.8 (95\% CI: 76.4 to 87.2 ) to 60.0 (95\% CI: 51.8 to 68.2 ) for annual leave (figure 2A,B). There was evidence that the NFR Score increased as the proportion of time working out-of-hours increased, from 54.5 (95\% CI: 47.8 to 61.3 ) to 81.8 (95\% CI: 75.4 to 88.3 ) (figure 2C). Over $75 \%$ of participants spent the majority of their time in adult EM with a median NFR Score of 72.7 for mixed or adult only, which was higher when compared with paediatrics only 63.6 (95\% CI: 55.2 to 72.1 ) (figure 2D). Most participants worked 1 in 2 weekends (36\%) with a median NFR Score of 72.7, which decreased to 54.5 for those who did not work any weekend shifts (see table 3 ). Over $50 \%$ reported working five to eight consecutive clinical shifts and had a median NFR Score of 72.7, compared with those who worked less than five who had a median NFR Score of $\leq 63.6$.

The summary statistics of the final regression model are presented in table 4.

This model was based on 3979 participants with complete data for all the included covariates. Quantile regression confirmed the direction and significance of the associations remained the same (online supplemental material 5). Each covariate was adjusted for all other statistically significant associations. The results from this model indicated there were statistically significant associations between gender, health conditions, type of ED (adult or paediatric), clinical grade, access to annual and study leave, and time spent working out-of-hours. The model suggested that males, GPs or consultants, those working in paediatrics and those with no long-term health condition or disability had the lowest NFR Score. The greatest increase in NFR Score was associated with those who reported more than a $75 \%$ proportion of outof-hours work (14.45: 95\% CI: 10.97 to 17.92). If participants strongly agreed they were able to obtain study leave on request this reduced their NFR Score by 6.5 (95\% CI: 3.56 to 9.43 ) and annual leave could reduce their NFR Score 4.89 (95\% CI: 1.72 to 8.06$)$.

\section{DISCUSSION}

Emergency physicians in the UK and Ireland have a higher NFR Score than has been reported in any previously studied population. ${ }^{1133-37}$ Three modifiable occupational factors were significantly associated with higher NFR scores (poor access to annual leave and study leave, and proportion of out-of-hours work), and four further non-modifiable demographic factors were associated with a decreased NFR Score. These were the senior grade of EM consultant, male gender, absence of long-term health 
Table 2 Summary statistics of NFR Score by participant's characteristics

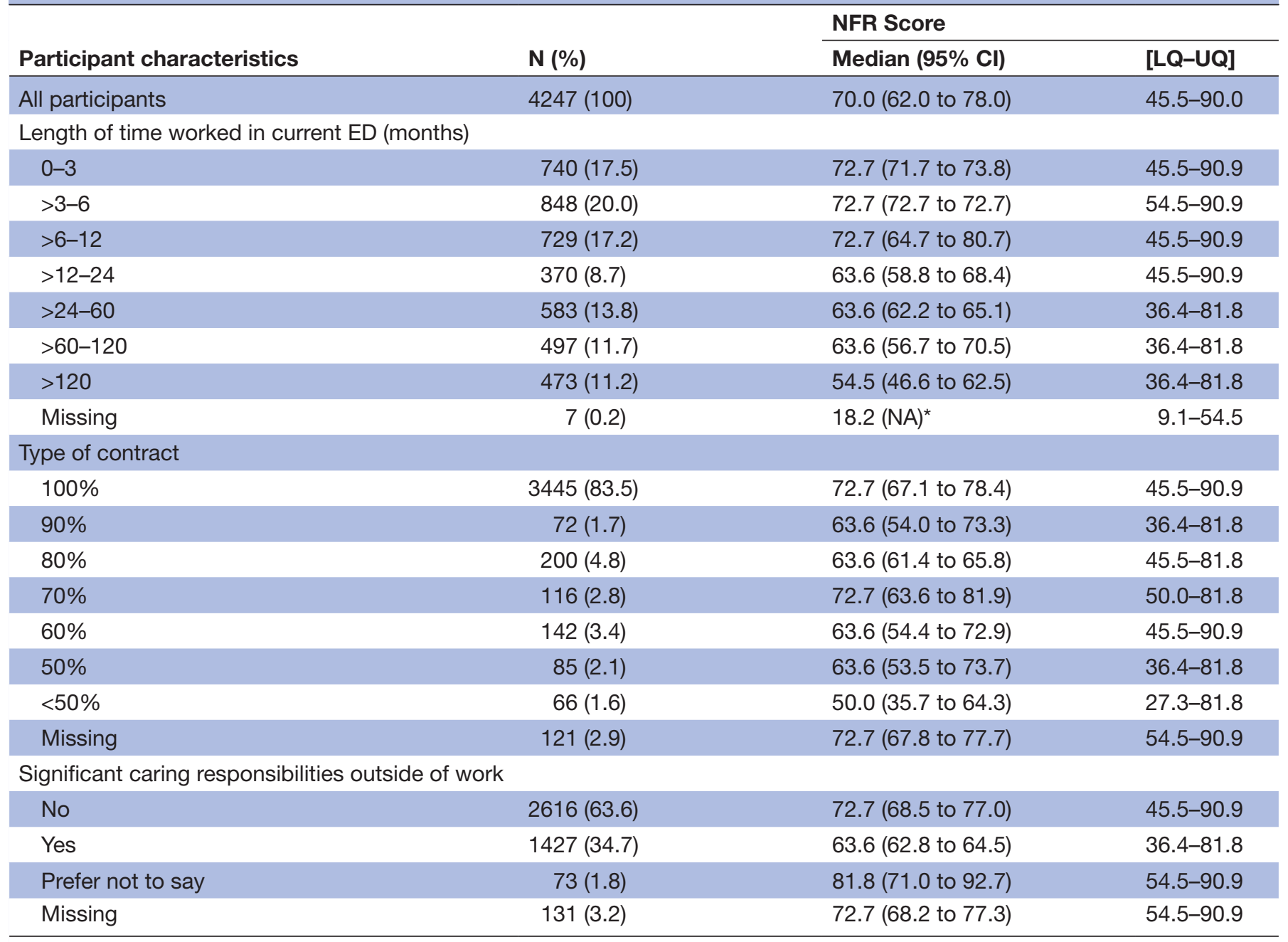

Frequency and percentage, median Need for Recovery (NFR) Score with 95\% bootstrapped Cls and the IQR of participants within each category.

*Insufficient observations for Bootstrapped 95\% Cls based.

$\mathrm{ED}$, emergency department; $L Q$, lower quartile; UQ, upper quartile.

condition or disability, and working in a paediatric only ED.

The NFR median Score of 70 found in this study compares unfavourably with multiple occupational groups and baseline population data from a large Dutch validation study, ${ }^{37}$ where the highest frequency of responses were observed at the lower end of the scale. Previous measurement in shift workers (including hospital nurses) showed significantly lower NFR scores, ${ }^{13} 33$ as did studies of heavy goods vehicle drivers and merchant seafarers, all with average NFR scores in the range $36-44 .{ }^{35} 36$ Our findings are, however, congruent with our own feasibility work completed in a single-centre UK ED, reporting a median NFR Score of 81.8 in all staff groups. ${ }^{21}$ The impact of rising patient numbers and overcrowding on UK and Ireland EDs is commonly reported, ${ }^{38} 39$ but our findings are the first to illustrate the impact of high work demand on physicians' need to recuperate from work and the modifiable factors which can mitigate this fatigue.
The three modifiable occupational factors represent areas of autonomy and control, correlating well with previous work establishing these as core drivers to minimise physician workplace stress and ensure well-being. ${ }^{24041}$ Prioritising change in these domains may result in NFR Score reduction and reduce negative effects on health and well-being, including occupational burnout. While out-of-hours working is inherent and unavoidable in EM, the linear relationship we observed suggests that any reduction may result in direct improvements in NFR, and evidence-based strategies such as proportional control of out-of-hours working, annualised rota patterns and/or provision of rest facilities should, therefore, be considered urgently. ${ }^{42-44}$

As NFR does not change with seniority prior to consultant level, this indicates that factors that could be postulated to influence work stress in postgraduate training, such as increased responsibility, management roles and experience, appear to have a limited influence on NFR. 
Table 3 Summary statistics of NFR Score by occupational characteristics

\begin{tabular}{|c|c|c|c|}
\hline \multirow[b]{2}{*}{ Occupational characteristics } & \multirow[b]{2}{*}{$\mathbf{N}(\%)$} & \multicolumn{2}{|l|}{ NFR Score } \\
\hline & & Median $(95 \% \mathrm{Cl})^{*}$ & [LQ-UQ] \\
\hline All participants & $4247(100)$ & 70.0 (62.0 to 78.0$)$ & $45.5-90.0$ \\
\hline 1 in 2 & $1479(36.0)$ & 72.7 (72.3 to 73.2$)$ & $54.5-90.9$ \\
\hline 1 in 3 & $865(21.1)$ & 72.7 (68.1 to 77.4$)$ & $45.5-90.9$ \\
\hline 1 in 5 & $310(7.5)$ & 54.5 (48.4 to 60.7$)$ & $36.4-81.8$ \\
\hline 1 in 6 & $485(11.8)$ & 54.5 (49.8 to 59.3$)$ & $27.3-81.8$ \\
\hline$<1$ in 6 & $307(7.5)$ & 63.6 (55.2 to 72.1$)$ & $36.4-81.8$ \\
\hline None & $121(2.9)$ & 54.5 (45.7 to 63.4$)$ & $27.3-81.8$ \\
\hline Missing & $138(3.4)$ & 72.7 (65.9 to 79.6$)$ & $45.5-90.9$ \\
\hline 3 & 465 (11.3) & $63.6(60.3$ to 67.0$)$ & $36.4-81.8$ \\
\hline 4 & 783 (19) & 63.6 (63.0 to 64.3$)$ & $45.5-81.8$ \\
\hline 5 & $827(20.1)$ & 72.7 (66.2 to 79.3$)$ & $45.5-81.8$ \\
\hline 6 & $389(9.5)$ & 72.7 (67.3 to 78.2$)$ & $45.5-90.0$ \\
\hline 7 & $855(20.8)$ & 72.7 (70.8 to 74.6$)$ & $45.5-90.9$ \\
\hline 8 & $554(13.5)$ & 72.7 (66.5 to 78.9$)$ & $54.5-90.9$ \\
\hline Missing & $132(3.2)$ & 72.7 (67.9 to 77.6$)$ & $54.5-90.9$ \\
\hline
\end{tabular}

Frequency and percentage, median Need for Recovery (NFR) Score with 95\% bootstrapped Cls and the IQR of participants within each category.

${ }^{*}$ Bootstrapped $95 \%$ Cls based on 1000 replications on a minimum of 8 observations. $\mathrm{LQ}$, lower quartile; UQ, upper quartile.

It is, therefore, possible that the reduction in NFR seen in those at consultant level supports the hypothesis that broader perceptions of job autonomy and control, may be explicitly linked to well-being in healthcare. ${ }^{244}$ This correlates with our finding that poor access to study and annual leave increases NFR, likely to be more accessible at a senior level. Further areas merit exploration including the link to out-of-hours working, influence of night and day shift proportions and possible qualitative enquiry of personal experience and clinical performance.

The relationship observed between gender and NFR is likely to be overly simplistic requiring further evaluation. Presumed confounding variables affecting this issue (such as a primary carer role and domestic responsibilities) have been previously reported to be unrelated or protective against maladaptive fatigue and are supported with findings from this study. ${ }^{45}$

Awareness of the four demographic factors identified could be important at a departmental planning level and increase advocacy for colleagues at greatest risk of impaired well-being.

The main strength of our study is inclusion of responses from over half of all UK EDs, enhancing generalisability of our findings. ${ }^{24}$ The high volume of responses indicates the NFR Scale as an 11-item survey, is an acceptable measure for physicians, with over half of sites exceeding $70 \%$ response rates. A key weakness is the single-point-of-time measurement, as seasonal bias may have affected NFR scores. Furthermore, we acknowledge the disadvantages of self-administered dichotomous questionnaires which may limit the richness of insights. ${ }^{46}{ }^{47}$ Open-ended questions may be desirable in future survey iterations.

The straightforward construction and interpretation, ease of administration and completion confers advantages of the NFR Scale over more complex well-being inventories allowing for quick assessment of a workforce NFR, especially in a busy clinical environment. Where identified to be high and interventions initiated such as a rota change, the NFR Scale can be easily repeated to confirm or refute the impact, and may identify further areas resulting in continual improvement while minimising survey respondent fatigue.

Future areas of work will include analysis of the NFR findings in relationship to well-being and burnout. Any future work should also include other ED staff groups and physician groups to gain a broader picture across the multiprofessional team. 
Table 4 Summary of final Gaussian, mixed effects, linear regression model fitted to the Need for Recovery (NFR) Score, including the adjusted coefficient estimate (Adj. Coef. Est.) with corresponding $95 \% \mathrm{Cl}$ and $\mathrm{p}$ value

\begin{tabular}{llc}
\hline & Adj. Coef. Est. (95\% Cl)* & P value† \\
\hline $\begin{array}{l}\text { Constant } \\
\text { (baseline NFR Score) }\end{array}$ & 59.51 (55.53 to 63.49$)$ & $<0.001$ \\
$\begin{array}{l}\text { Gender (baseline=male) } \\
\text { Female }\end{array}$ & 3.40 (1.80 to 4.99$)$ & $<0.001$ \\
\hline $\begin{array}{l}\text { Other/prefer not to say } \\
\text { Any long-term health conditions or disabilities (baseline=no) }\end{array}$ & $-0.46(-9.07$ to 8.15$)$ & 0.916 \\
\hline Yes & $8.52(5.67$ to 11.36$)$ & $<0.001$ \\
\hline Prefer not to say & $6.24(1.52$ to 10.95$)$ & 0.01 \\
\hline ED paediatrics only (baseline=no) & \\
\hline Yes & $-7.08(-10.4$ to -3.77$)$ & $<0.001$ \\
\hline Clinical grade (baseline=foundation) & 0.953 \\
\hline ST1-ST2 & $-0.08(-2.67$ to 2.51$)$ & 0.336 \\
\hline >ST2 & $1.32(-1.37$ to 4.01$)$ & 0.482 \\
\hline SASG & $-1.13(-4.27$ to 2.02$)$ & 0.018 \\
\hline GP & $-8.26(-15.09$ to -1.44$)$ & $<0.001$ \\
\hline Consultant & $-5.30(-8.07$ to -2.53$)$
\end{tabular}

I have been able to request and take study when I wanted (baseline=neutral)

\begin{tabular}{|c|c|c|}
\hline Strongly disagree & $4.23(-0.26$ to 8.71$)$ & 0.065 \\
\hline Disagree & $3.72(0.29$ to 7.15$)$ & 0.034 \\
\hline Agree & $-1.32(-3.60$ to 0.96$)$ & 0.257 \\
\hline Strongly agree & $-6.50(-9.43$ to -3.56$)$ & $<0.001$ \\
\hline \multicolumn{3}{|c|}{$\begin{array}{l}\text { I have been able to request and take annual when I wanted } \\
\text { (baseline=neutral) }\end{array}$} \\
\hline Strongly disagree & $6.43(2.03$ to 10.83$)$ & 0.004 \\
\hline Disagree & $1.13(-2.34$ to 4.61$)$ & 0.523 \\
\hline Agree & $-2.84(-5.54$ to -0.14$)$ & 0.039 \\
\hline Strongly agree & $-4.89(-8.06$ to -1.72$)$ & 0.002 \\
\hline \multicolumn{3}{|c|}{ Proportion of time spent working out-of-hours (baseline $=0 \%-25 \%$ ) } \\
\hline $26 \%-50 \%$ & 5.74 (3.13 to 8.35$)$ & $<0.001$ \\
\hline $51 \%-75 \%$ & $10.32(7.60$ to 13.03$)$ & $<0.001$ \\
\hline $76 \%-100 \%$ & 14.45 (10.97 to 17.92$)$ & $<0.001$ \\
\hline
\end{tabular}

*Each coefficient estimate is adjusted for all other covariates in the model.

†Null hypothesis: Adj. Coef. Est. $=0$ (ie, is there statistically significant evidence this category differs from the baseline category). ED, emergency department; GP, General Practitioner working within the ED; SASG, emergency medicine staff grade, associate specialist and speciality grade physician; ST1-ST2, specialist training year 1-2 (this included physicians training in anaesthetics, emergency medicine, acute medicine and general practice).

In conclusion, this study provides a robust estimate of the NFR for emergency physicians in the UK and Ireland, which is higher than any occupation reported to date. Several potentially modifiable occupational characteristics were associated with higher NFR, and future work to assess the impact of modifying these factors will inform strategies to reduce NFR. In time, this may lead to improved long-term physician well-being and enhanced staff retention.

\section{Author affiliations}

${ }^{1}$ Emergency Department, University Hospitals Plymouth NHS Trust, Plymouth, UK ${ }^{2}$ Academic Department of Military Emergency Medicine, Royal Centre for Defence Medicine, Birmingham, UK

${ }^{3}$ The Royal College of Emergency Medicine, London, UK

${ }^{4}$ Faculty of Health, University of Plymouth, Plymouth, UK

${ }^{5}$ Emergency Department, Salford Royal Hospitals NHS Trust, Salford, UK

${ }^{6}$ Division of Infection, Immunity and Respiratory Medicine, University of Manchester, Manchester, UK

${ }^{7}$ Medical Statistics Group, Faculty of Medicine and Dentistry, University of Plymouth, Plymouth, UK

${ }^{8}$ Research Design Service East Midlands, University of Nottingham, Nottingham, UK ${ }^{9}$ Emergency Department, Bristol Royal Hospital for Children, Bristol, UK

${ }^{10}$ Faculty of Health and Applied Science, University of the West of England, Bristol, UK

Correction notice The article has been corrected since it is published. The Collaborators section has been added in the republished version.

Twitter Laura Cottey @lauracottey and Mark David Lyttle @mdlyttle

Acknowledgements The authors would like to thank the Royal College of Emergency Medicine and University Hospitals Plymouth NHS Trust Research and Development Department for their support with the study. In addition, we like to thank the following individuals for study input: Professor Jason E Smith for providing feedback on study design; Victoria Yates and Dr Chris Rollinson for their support as study sponsorship team; Mark Mills for conducting data analysis for the feasibility work; Dr Ffion Barham for providing assistance with initial data analysis; Professor Marc van Veldhoven for kind permission to use the Need for Recovery Scale. Finally, we would like to acknowledge Ireland Trainee Emergency Research Network, for their invaluable support recruiting patients to the study within Ireland.

Collaborators List of Trainee Emergency Research Network and Paediatric Emergency Research in the UK and Ireland collaborators Site study leads (136) L Kane (Aberdeen Royal Infirmary); S Richter, J Selway (Addenbrooke's Hospital, Cambridge); C Rimmer (Aintree Hospital, Liverpool); M Ayres (Airedale General Hospital, West Yorkshire); C Ponami (Barking, Havering and Redbridge University Hospitals NHS Trust); A Quartermain (Basingstoke and North Hampshire Hospital); K Kaur (Bedford Hospital); S Hartshorn (Birmingham Children's Hospital); K McGregor (Bradford Royal Infirmary); G Gardner (Bristol Royal Hospital for Children), T Clingo (Bristol Royal Infirmary); R Stewart (Chelsea \& Westminster Hospital); N Mullen (South Tyneside and Sunderland NHS Foundation Trust); K Mirza (Colchester Hospital); T Hussan (County Durham and Darlington NHS Foundation Trust); P Cuthbert (Craigavon Area Hospital, County Armagh); M Alex (Croydon University Hospital); F Barham (Derriford Hospital, Plymouth), A Bayston (Doncaster and Bassetlaw Hospital NHS Trust); K Veeramuthu (East Surrey Hospital); R Macfarlane (Epsom and St Helier NHS Trust); J Criddle (Evelina London Children's Hospital); G Lipton (Forth Valley Royal Hospital); K New (Frimley Park Hospital); M Jee Poh Hock, E Umana (Galway University Hospital, Republic of Ireland); C Ward (Glasgow Royal Infirmary); V Agosti, M Connelly (Gloucestershire Hospitals Foundation Trust); C Weegenaar (Great Western Hospital, Swindon); J Kerr (Hampshire Hospitals NHS Trust); SJ Dhutia, T Owens (Homerton University Hospital); B Cherian (Hull University Teaching Hospital); U Basit, D Hartin (Ipswich Hospital); 0 Williams (James Cook University Hospital, Middlesbrough); C Lindsay (James Paget University Hospital); F Cantle (King's College Hospital, London); S Manou (Leeds Teaching Hospitals NHS Trust); MH Elwan, C Nunn (Leicester Royal Infirmary); R Fuller (Leighton Hospital, Crewe); S Stevenson (Limerick Regional Hospital, Republic of Ireland); C Reynard (Manchester University NHS Foundation Trust); J Daly (Mater Misericordiae University Hospital, Republic of Ireland; A Da'Costa (Medway Foundation NHS Trust); L How (Milton Keynes Hospital); G Boggaram, D McConnell (Musgrove Park Hospital, Taunton); R Hirst, K Thomas (North Bristol NHS Trust); R Campbell, J Muller, S Taylor (North Middlesex University Hospital); H Chatha (Northern General Hospital, Sheffield); R Grimwood (Northumbria Specialist Emergency Care Hospital); F Fadhlillah (Northwick Park Hospital); UM Khan, S 0jo (Nottingham University Hospitals Trust); A Paul, S Ramsundar (Oxford University Hospital); A Blackwell, DSD Ranasinghe (Queen Alexandra Hospital, Portsmouth); S Hall (Queen Elizabeth Hospital, Woolwich); I Traiforos (Queen Elizabeth University Hospital, Glasgow); E Walton (Royal Alexandra Children's Hospital, Brighton); T Sparkes (Royal Berkshire Hospital); L Barrett (Royal Blackburn Hospital); M Sheikh (Royal Bolton Hospital); 
J Driessen (Royal Cornwall Hospital); S Meredith, C Newbury (University of Derby and Burton Hospitals Trust); H Grimsmo-Powney, H Malik (Royal Devon and Exeter Hospital); L Gwatkin (Royal Gwent Hospital); R Blackburn, L McKechnie (Royal Hospital for Children, Glasgow); J Browning (Royal Hospital for Sick Children, Edinburgh); F Gillies (Royal Infirmary of Edinburgh); TF McLoughlin (Royal Liverpool University Hospital); SM Rahman (Royal London Hospital); K Hopping (Royal Manchester Children's Hospital); M Broydé (Royal Oldham Hospital); K Challen, M Macdonald (Royal Preston Hospital); A Randle (Royal Shrewsbury Hospital); E Timony-Nolan (Royal Sussex County Hospital, Brighton); H Fairbairn (Royal United Hospital, Bath); G Gracey (Royal Victoria Hospital, Belfast); K Clayton, J Thompson (Royal Victoria Infirmary Hospital, Newcastle); C Kennedy (Salford Royal Hospital); S Gray (Salisbury NHS Foundation Trust); C Magee (Sandwell General Hospital, Birmingham); G Hartshorne (Sheffield Children's Hospital); J Foley (Sligo University Hospital, Republic of Ireland); S Gardner, S Pintus, K Scott (Southport \& Ormskirk Hospital); K Brammer, A Raghunathan (St Georges Hospital, Tooting); S Langston (St Helen's and Knowsley NHS Trust); F Gillies (St John's Hospital, Livingston); J Patel (St Marys Hospital, London); A Knight (St Richards Hospital, Chichester); S Saunder, C Thomas (St Thomas' Hospital, London); C Szekeres (Surrey and Sussex NHS Trust); P Fitzpatrick (Temple Street Children's Hospital); L Kehler (The Royal Wolverhampton NHS Trust); H Cooper (Tunbridge Wells Hospital); B O'Hare (Ulster Hospital); A Arumugam, C Leech (University Hospitals Coventry and Warwickshire NHS Trust); Y Moulds, DL Thom (University Hospital Crosshouse); N Ali (University Hospital Lewisham, London); A Mackay (University Hospital Monklands); J Norton (University Hospital of North Midlands); E Frost, R Wright (University Hospital Southampton); CE Davies, A Hanks, E Murray (University Hospital of Wales); A Saunders (Victoria Hospital, Kirkcaldy); KI Malik (West Suffolk Hospital); IMV Asif (West Middlesex Hospital); S Manouchehri (Wexham Park Hospital); A Fatkin, S Lewis (Whiston Hospital); S Naeem (William Harvey Hospital, Ashford); A Basu (Wrexham Maelor Hospital); N Cherian, 0 Hill (Wythenshawe Hospital, Manchester); C Boulind (Yeovil District Hospital); P Williams (Ysbyty Gwynedd Hospital) Data collectors (46) S Hardwick, C Gandolfi (Addenbrooke's Hospital, Cambridge); E Everitt (Aintree Hospital, Liverpool); R Hughes (Betsi Cadwaladr University Hospital); E Williams (Bristol Royal Hospital for Children), A Ghosh (Colchester Hospital); G Hampton, D McKeever, D Purdy, L Savage (Craigavon Area Hospital); S Bailey (Derriford Hospital, Plymouth); J Leung (East Kent Hospitals); L Brown, P Harris, R Sharr (East Surrey Hospital); L Evans, S Helyer (Epsom and St Helier NHS Trust); R Loffhagen (Gloucestershire Hospitals Foundation Trust); V Rivers (Ipswich Hospital); HD Khan, K Vincent (Leicester Royal Infirmary), H Baird (Manchester University NHS Foundation Trust); J Foot (Musgrove Park Hospital, Taunton); S Bury, E Grocholski, G Kamalatharan (Northwick Park Hospital); J Gaiawyn (Royal Cornwall Hospital); G Johnson, A Tabner (University of Derby and Burton Hospitals Trust); L Abraham (Royal Devon and Exeter Hospital); N Sexton (Royal Liverpool University Hospital); A Akhtar (Royal Victoria Hospital, Belfast); C de Buitleir (Sligo University Hospital, Republic of Ireland); B Clarke, M Colmar (St John's Hospital, Livingston); Z Haslam, M Morrison (Southport \& Ormskirk NHS Trust); K Veermuthu (Surrey and Sussex Healthcare Trust); D Raffo, J Stafford (Ulster Hospital, Belfast); S Mclintock (University Hospitals Coventry and Warwickshire NHS Trust); R Bond, OR Griffiths, B Mcllwham (University Hospital Wales); K Cunningham (Victoria Hospital, Kirkcaldy); E Clegg (Wythenshawe Hospital)

Contributors LC, TR and BG contributed to the development of the study design, data collection and analysis, the first draft of the manuscript and subsequent revised versions. DH and JL contributed to the development of the study design, data analysis, the first draft of the manuscript and subsequent revised versions. MDL contributed to survey development, data collection and final version of manuscript; KNS and DE provided the statistical analysis plan and contributed to data analysis, the first draft of the manuscript and subsequent revised versions. All authors approved the final version of the manuscript for submission. LC is the guarantor. Trainee Emergency Research Network and Paediatric Emergency Research in the UK and Ireland collaborators contributed to local study promotion and participant recruitment.

Funding This project was funded through a grant from the Royal College of Emergency Medicine (RCEM) (Reference number: G/2018/1). This study was independent of RCEM, and the sponsor had no role in the design of this study and no role during its execution, analyses, interpretation of the data, or decision to submit results.

Competing interests TR has received $50 \%$ salary funding for 2 years as the Trainee Emergency Research Network fellow from the Royal College of Emergency Medicine; DH reported an honorary role as the Professor of the Royal College of Emergency Medicine during the conduct of this study.

Patient consent for publication Not required.
Ethics approval This study protocol was submitted through the Integrated Research Application System (IRAS), IRAS number 262048 and received proportionate ethical approval by the Health Research Authority and Health and Care Research Wales, Research Ethics Committee reference 19/HRA/2404 and equivalent approvals in Scotland, Northern Ireland and Ireland. All participants provided informed consent prior to beginning the survey.

Provenance and peer review Not commissioned; externally peer reviewed.

Data availability statement Data are available upon reasonable request. Deidentified participant level data by site will be made available on reasonable request through the study team (tern@rcem.ac.uk). Data will be available for researchers whose proposed use of the data has been approved by the study team.

Supplemental material This content has been supplied by the author(s). It has not been vetted by BMJ Publishing Group Limited (BMJ) and may not have been peer-reviewed. Any opinions or recommendations discussed are solely those of the author(s) and are not endorsed by BMJ. BMJ disclaims all liability and responsibility arising from any reliance placed on the content. Where the content includes any translated material, BMJ does not warrant the accuracy and reliability of the translations (including but not limited to local regulations, clinical guidelines, terminology, drug names and drug dosages), and is not responsible for any error and/or omissions arising from translation and adaptation or otherwise.

Open access This is an open access article distributed in accordance with the Creative Commons Attribution Non Commercial (CC BY-NC 4.0) license, which permits others to distribute, remix, adapt, build upon this work non-commercially, and license their derivative works on different terms, provided the original work is properly cited, appropriate credit is given, any changes made indicated, and the use is non-commercial. See: http://creativecommons.org/licenses/by-nc/4.0/.

\section{ORCID iDs}

Laura Cottey http://orcid.org/0000-0002-4045-9444

Tom Roberts http://orcid.org/0000-0003-4991-974X

Blair Graham http://orcid.org/0000-0002-0005-0476

Daniel Horner http://orcid.org/0000-0002-0400-2017

Kara Nicola Stevens http://orcid.org/0000-0003-4898-1795

Doyo Enki http://orcid.org/0000-0003-1532-8992

Mark David Lyttle http://orcid.org/0000-0002-8634-7210

Jos Latour http://orcid.org/0000-0002-8087-6461

\section{REFERENCES}

1 The King's Fund. The health care workforce in England: make or break? 2018. Available: https://www.kingsfund.org.uk/publications/ health-care-workforce-england [Accessed 27 May 2020].

2 UK-wide review of doctors and medical students wellbeing - GMC, 2019. Available: https://www.gmc-uk.org/about/how-we-work/ corporate-strategy-plans-and-impact/supporting-a-professionunder-pressure/uk-wide-review-of-doctors-and-medical-studentswellbeing [Accessed 27 May 2020].

3 Ramirez AJ, Graham J, Richards MA, et al. Mental health of hospital consultants: the effects of stress and satisfaction at work. Lancet 1996;347:724-8.

4 Salen P, Norman K. The impact of fatigue on medical error and clinician wellness: a Vignette-Based discussion. In: Vignettes in Patient Safety - Volume 2. 2, 2018.

5 Arora M, Asha S, Chinnappa J, et al. Review article: burnout in emergency medicine physicians. Emerg Med Australas 2013;25:491-5

6 Han S, Shanafelt TD, Sinsky CA, et al. Estimating the attributable cost of physician burnout in the United States. Ann Intern Med 2019;170:784.

7 Rotenstein LS, Torre M, Ramos MA, et al. Prevalence of burnout among physicians: a systematic review. JAMA 2018;320:1131-50.

8 Shanafelt TD, Hasan O, Dyrbye LN, et al. Changes in burnout and satisfaction with work-life balance in physicians and the general us working population between 2011 and 2014. Mayo Clin Proc 2015;90:1600-13.

9 The Lancet T. Physician burnout: a global crisis. Lancet 2019;394:93

10 West CP, Dyrbye LN, Erwin PJ, et al. Interventions to prevent and reduce physician burnout: a systematic review and meta-analysis. Lancet 2016;388:2272-81

11 Sluiter JK, van der Beek AJ, Frings-Dresen $\mathrm{MH}$. The influence of work characteristics on the need for recovery and experienced health: a study on coach drivers. Ergonomics 1999;42:573-83. 
12 Jansen N, Kant I, van Amelsvoort L, et al. Need for recovery from work: evaluating short-term effects of working hours, patterns and schedules. Ergonomics 2003;46:664-80.

13 Sluiter JK, de Croon EM, Meijman TF, et al. Need for recovery from work related fatigue and its role in the development and prediction of subjective health complaints. Occup Environ Med 2003;60 Suppl 1:62i-70.

14 Sluiter JK, Frings-Dresen $\mathrm{MH}$, van der Beek AJ, et al. The relation between work-induced neuroendocrine reactivity and recovery, subjective need for recovery, and health status. J Psychosom Res 2001;50:29-37.

15 GMC. General medical Council. National training surveys 2019: initial findings report, 2019. Available: https://www.gmc-uk.org/-/media/ gmc-site-images/about/national-training-surveys-initial-findingsreport-20190705 2.pdf?la=en\&hash $=8455783$ A3C4DE2CC55A3 8ACB9ACF5D0B391744B0 [Accessed 27 May 2020].

16 Williamson K, Lank PM, Cheema N, et al. Comparing the Maslach burnout inventory to other well-being instruments in emergency medicine residents. J Grad Med Educ 2018;10:532-6.

17 Boutou A, Pitsiou G, Sourla E, et al. Burnout syndrome among emergency medicine physicians: an update on its prevalence and risk factors. Eur Rev Med Pharmacol Sci 2019;23:9058-65.

18 Panagioti M, Panagopoulou E, Bower $\mathrm{P}$, et al. Controlled interventions to reduce burnout in physicians: a systematic review and meta-analysis. JAMA Intern Med 2017;177:195-205.

19 Dewa CS, Jacobs $P$, Thanh NX, et al. An estimate of the cost of burnout on early retirement and reduction in clinical hours of practicing physicians in Canada. BMC Health Serv Res 2014;14:254.

20 National Academies of Sciences E and M. Taking action against clinician burnout. Washington, D.C: National Academies Press, 2019

21 Graham B, Cottey L, Smith JE, et al. Measuring 'Need for Recovery' as an indicator of staff well-being in the emergency department: a survey study. Emerg Med J 2020;37:555-61.

22 Smith J, Keating L, Flowerdew L, et al. An emergency medicine research priority setting partnership to establish the top 10 research priorities in emergency medicine. Emerg Med J 2017;34:454-6.

23 Eysenbach $\mathrm{G}$. Improving the quality of web surveys: the checklist for reporting results of Internet E-Surveys (cherries). J Med Internet Res 2004;6:e34

24 Medicine RC of E. Essential Facts Regarding A\&E Services, 2018. Available: https://www.rcem.ac.uk/docs/Policy/England Factsheet 2018.pdf [Accessed 27 May 2020].

25 Cottey L, Vassallo J, Roberts T, et al. About TERN? - RCEMLearning. Available: https://www.rcemlearning.co.uk/foamed/about-tern/ [Accessed 27 May 2020].

26 Lyttle MD, O'Sullivan R, Hartshorn S, et al. Pediatric emergency research in the UK and ireland (PERUKI): developing a collaborative for multicentre research. Arch Dis Child 2014;99:602-3.

27 Van Veldhoven M, Meijman TF. Het Meten van Psychosociale Arbeidsbelasting Met EEN Vragenlijst: de Vragenlijst Beleving en Beoordeling van de Arbeid (VBBA) (Zie VBBA2.0 voor nieuwe versie, 1994.

28 van Veldhoven M, Broersen S. Measurement quality and validity of the "need for recovery scale". Occup Environ Med 2003;60 Suppl 1:3i-9.

29 Harris PA, Taylor R, Minor BL, et al. The REDCap Consortium: building an international community of software platform partners. $J$ Biomed Inform 2019:95:103208.
30 Harris PA, Taylor R, Thielke R, et al. Research electronic data capture (REDCap)--a metadata-driven methodology and workflow process for providing translational research informatics support. J Biomed Inform 2009;42:377-81.

31 StataCorp. Stata statistical software: release 14. College Station, TX: StataCorp LP, 2015.

32 van der Starre RE, Coffeng JK, Hendriksen IJM, et al. Associations between overweight, obesity, health measures and need for recovery in office employees: a cross-sectional analysis. BMC Public Health 2013;13. doi:10.1186/1471-2458-13-1207

33 Moriguchi CS, Trevizani T, De Fátima Moreira R, et al. Need for recovery assessment among nursing professionals and call center operators. In: Work, 2012: 4838-42.

34 Samadi H, Kalantari R, Mostafavi F, et al. Using the need for recovery scale to assess workload in mine workers and its relationship with demographics. J Ergon 2017;4:1-7.

35 Bridger RS, Brasher K, Dew A. Work demands and need for recovery from work in ageing seafarers. Ergonomics 2010;53:1006-15.

36 de Croon EM, Sluiter JK, Frings-Dresen MHW. Need for recovery after work predicts sickness absence: a 2-year prospective cohort study in truck drivers. J Psychosom Res 2003;55:331-9.

37 Jansen NWH, Kant IJ, van den Brandt PA. Need for recovery in the working population: description and associations with fatigue and psychological distress. Int J Behav Med 2002;9:322-40.

38 Hassan T, Walker B, Harrison M, et al. Stretched to the limit: a survey of emergency medicine consultants in the UK, 2013. Available: www. rcem.ac.uk/docs/Policy/CEM7461-Stretched-to-the-limit-October 2013.pdf [Accessed 27 May 2020].

39 The Royal College of Emergency Medicine. Improving safety in the emergency department this winter: a guide for health service leaders and boards, 2018. Available: https://www.rcem.ac.uk/RCEM/Quality Policy/Policy/Winter_Planning/RCEM/Quality-Policy/Policy/Winter_ Planning.aspx?hkey=e37845aa-c9a5-4b01-aa72-48137cc59aa1 [Accessed 23 July 2020].

40 Hall LH, Johnson J, Heyhoe J, et al. Strategies to improve general practitioner well-being: findings from a focus group study. Fam Pract 2018;35:511-6.

41 Galletta M, Portoghese I, Fabbri D, et al. Empowering workplace and wellbeing among healthcare professionals: the buffering role of job control. Acta Biomed 2016;87 Suppl 2:61-9.

42 NHS Improvement. Annualised hours rotas for emergency department doctors, 2019. Available: https://improvement.nhs.uk/ documents/5919/Brighton_Sussex_-_annualised_hours_rotas.pdf [Accessed 27 May 2020].

43 Rimmer A. Government commits $£ 10 m$ to doctors' rest facilities. BMJ 2019;365:I2233.

44 Smith E, Dasan S. A system under pressure. Br J Hosp Med 2018;79:495-9.

45 Winwood PC, Winefield $\mathrm{AH}$, Lushington K. Work-Related fatigue and recovery: the contribution of age, domestic responsibilities and shiftwork. J Adv Nurs 2006;56:438-49.

46 Dykema J, Jones NR, Piché T, et al. Surveying clinicians by web: current issues in design and administration. Eval Health Prof 2013;36:352-81.

47 Klabunde CN, Willis GB, McLeod CC, et al. Improving the quality of surveys of physicians and medical groups: a research agenda. Eval Health Prof 2012;35:477-506. 